\title{
Pseudopolymorphic transitions of niclosamide monitored by Raman spectroscopy
}

\author{
Mariana Sardo, ${ }^{1}$ Ana M. Amado ${ }^{2}$ and Paulo J. A. Ribeiro-Claro ${ }^{1 *}$ \\ ${ }^{1}$ CICECO, Departamento de Química, Universidade de Aveiro, P-3810-193 Aveiro, Portugal \\ ${ }^{2}$ Química-Física Molecular, Departamento de Química, FCTUC, Universidade de Coimbra, P-3004-535 Coimbra, Portugal
}

Received 29 January 2008; Accepted 28 May 2008

\begin{abstract}
Niclosamide suffers pseudopolymorphic transformations when exposed to different ambient conditions, which can lead to changes in its bioavailability. In this study, the kinetics of the pseudopolymorphic transitions of niclosamide crystals are characterized. FT-Raman spectroscopy is used to quantify the anhydrate and hydrate forms of niclosamide crystals, mostly because of its high sensitivity to the strong intermolecular interactions present in these systems. The samples are exposed to well-characterized relative humidity (RH) conditions during different periods of time and both water diffusion and polymorphic changes are monitored from the corresponding changes observed in the vibrational spectra. Both hydration and dehydration were found to be single-step processes, with a half-life time of $c a .142$ and $63 \mathrm{~h}$, respectively, at $24^{\circ} \mathrm{C}$. Copyright $\odot 2008$ John Wiley \& Sons, Ltd.
\end{abstract}

Supporting information may be found in the online version of this article.

KEYWORDS: niclosamide; hydration/dehydration; Raman spectroscopy; relative humidity; kinetics

\section{INTRODUCTION}

The phenomenon of polymorphism and pseudopolymorphism - solvates in general, hydrates in particular - is very common among pharmaceuticals and has been widely reported in the literature. ${ }^{1-6}$ Approximately one-third of pharmaceutical solids are able to form hydrate species, depending on the temperature and humidity conditions. ${ }^{7}$ Polymorphism/pseudopolymorphism reported by a given drug has become a major concern for pharmaceutics, since it has been recognized that differential crystal structures of a given chemical might exhibit different biopharmaceutical properties such as solubility, stability, and/or bioavailability. ${ }^{8,9}$ The unexpected occurrence of polymorphic or pseudopolymorphic transitions may lead to severe pharmaceutical consequences, which can result in product development delay and commercial production disruption, as in the case of ritonavir. ${ }^{10,11}$ Hydration and dehydration processes of a pharmaceutical solid during formulation development or in a final dosage form may adversely affect the physical, chemical, and/or biological performance of a pharmaceutical product. ${ }^{12}$

When polymorphism/pseudopolymorphism is known to occur, spectral methods of analysis can be of great value

*Correspondence to: Paulo J. A. Ribeiro-Claro, CICECO, Departamento de Química, Universidade de Aveiro, P-3810-193 Aveiro, Portugal. E-mail: prc@ua.pt to assess the drug's behavior. Vibrational spectroscopy contains information about the motions of functional groups in the solid and is often site-specific in nature, providing some insights as to the origins of the structural variations. ${ }^{9}$

Raman spectroscopy is finding increasing application in the field of pharmaceutical analysis ${ }^{13}$ due to its wellknown advantages over Fourier transform infrared (FTIR) spectroscopy for this type of study. The versatility of Raman spectroscopy allows the identification of polymorphic forms during crystallization, drying, milling, and granulation processes even in the presence of excipient, behind glass or in water. ${ }^{14-16}$ Moreover, Raman spectroscopy reveals changes in vibrations of the drug molecule during hydrate formation, and provides an excellent method for probing solidstate hydrogen-bonding interactions between molecules, including polymorphs and solvates. ${ }^{8,13-23}$

Niclosamide (5-chloro-N(2-chloro-4-nitrophenyl)-2-hydroxybenzamide, hereafter named NC, Fig. 1) is used as an anthelmintic, mainly for the treatment of worm infestations in humans and animals, namely, ruminants, ostriches, poultry, cats, and dogs. ${ }^{24} \mathrm{~A}$ significant antituberculosis activity for NC was also found in previous studies, with a minimal inhibitory concentration of 0.5 to $1 \mu \mathrm{g} \mathrm{ml}^{-1} .25$

Many studies indicate that NC crystallizes into a number of solvated forms, two monohydrates (usually labeled as $\mathrm{H}_{\mathrm{A}}$ and $\mathrm{H}_{\mathrm{B}}$ ) and one anhydrous form. ${ }^{24,26}$ It is well documented 


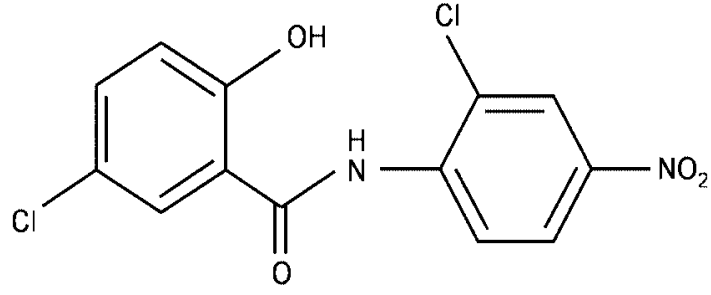

Figure 1. Schematic representation of niclosamide.

that NC is sensitive to polymorphic and pseudopolymorphic transformations that affect its dissolution profiles and, consequently, its bioavailability. ${ }^{24,26-28}$

Changes in relative humidity $(\mathrm{RH})$ conditions promote reversible conversion between the anhydrous form (hereafter named as $\mathrm{NCa}$ ) and the $\mathrm{H}_{\mathrm{A}}$ monohydrate (hereafter named as NCh). ${ }^{24,26}$ Other possible polymorphs/pseudopolymorphs described in the literature (such as $\mathrm{H}_{\mathrm{B}}$ monohydrate) are not part of this conversion path. The hydrated form is expected to present hydrogen-bonding networks involving water molecules, which are absent in the NCa form. These structural differences have a direct effect on the vibrational spectra (both in the position and in the relative intensities of the bands), as confirmed by the spectroscopic data available. ${ }^{24}$

In a previous work, the experimental methodology used to study the reversible hydration $\leftrightarrow$ dehydration processes by Raman spectroscopy (sample preparation, milling degree, temperature, humidity, and analysis technique) was found to yield reproducible kinetic parameters. ${ }^{15}$ Moreover, the use of Raman spectroscopy has the advantage of allowing simultaneous determination of the kinetic parameters of the process and of the structural changes underlying it. The ability to monitor the physico-chemical changes of materials is of utmost importance in product development, particularly in the pharmaceutical industry. In the present work, the reversible hydration $\leftrightarrow$ dehydration processes of NC are monitored by means of FT-Raman spectroscopy, aimed at the characterization of kinetic parameters as well as solid-state transformations for this pharmaceutically active compound.

\section{MATERIALS AND METHODS}

\section{NC samples}

Anhydrous niclosamide (NCa) was obtained commercially (Sigma-Aldrich) and used after 1 week exposure to $0 \% \mathrm{RH}$ conditions (grain size between 125 and $250 \mu \mathrm{m}$ ). Identical results are obtained by exposure of the sample to a temperature of $100^{\circ} \mathrm{C}$.

Niclosamide monohydrate $(\mathrm{NCh})$ was prepared by dissolving $\mathrm{NCa}$ in distilled water at $60^{\circ} \mathrm{C}$ until a supersaturated solution was obtained. When the solution was allowed to slowly cool at room temperature, crystals of the monohydrate were formed. These were filtered from the mother liquid, allowed to dry at ambient conditions (temperature and $\mathrm{RH}$ ), and gently milled to a fine powder (grain size between 125 and $250 \mu \mathrm{m}$ ). Identical results are obtained by exposure of NCa to $100 \%$ RH conditions for 2 weeks.

Physical mixtures of known composition (for calibration purposes) were prepared by gently mixing the samples in a mortar, without grinding. Each calibration mixture was prepared three times and three samples of the same mixture were measured in order to discard problems with homogeneity.

The crystalline degree of the samples was evaluated by powder X-ray diffraction (PXRD). The diffraction patterns of the NCh and NCa samples are in good agreement with the reported patterns of fully crystalline samples..$^{24,26,27}$

\section{Sample treatment}

Approximately $0.05 \mathrm{~g}$ of the NCa and NCh samples were transferred to small glass reservoirs and exposed to defined $\mathrm{RH}$ conditions (inside weighing bottles). Using the experimental apparatus described in Fig. 2, without direct contact between the sample and the bulk liquid, the samples were exposed to different $\mathrm{RH}$ conditions which were created by using saturated salt solutions with deposit. The $R H$ values considered (and respective salt used) were taken from the literature ${ }^{29}$ and are as follows: $6 \%(\mathrm{NaOH}), 9 \%(\mathrm{KOH}), 13 \%$ ( $\mathrm{LiCl}), 20 \%\left(\mathrm{KC}_{2} \mathrm{H}_{3} \mathrm{O}_{2}\right), 30 \%\left(\mathrm{CaCl}_{2}\right), 42 \%\left[\mathrm{Zn}\left(\mathrm{NO}_{3}\right)_{2}\right], 48 \%$ $(\mathrm{KSCN}), 52 \%\left(\mathrm{NaHSO}_{4}\right), 58 \%(\mathrm{NaBr}), 61 \%\left(\mathrm{NH}_{4} \mathrm{NO}_{3}\right), 66 \%$ $\left(\mathrm{NaNO}_{2}\right), 78 \%\left(\mathrm{Na}_{2} \mathrm{SO}_{3}\right), 79 \%\left(\mathrm{NH}_{4} \mathrm{Cl}\right), 81 \%\left[\left(\mathrm{NH}_{4}\right)_{2} \mathrm{SO}_{4}\right]$, $84 \%(\mathrm{KBr}), 86 \%\left(\mathrm{KHSO}_{4}\right), 90 \%\left(\mathrm{BaCl}_{2} \cdot 2 \mathrm{H}_{2} \mathrm{O}\right), 92 \%\left(\mathrm{KNO}_{3}\right)$, and $97 \%\left(\mathrm{~K}_{2} \mathrm{SO}_{4}\right)$. The $\mathrm{RH}$ values corresponding to 0 and $100 \%$ were achieved by considering silica and pure water, respectively. The reproducibility of $\mathrm{RH}$ conditions was carefully monitored by repeated experiments.

The $\mathrm{H}_{2} \mathrm{O}$ loss/uptake due to exposure to different $\mathrm{RH}$ conditions was also monitored by sample weighting for a set of separate samples. The $1 \mathrm{~mol} \mathrm{H}_{2} \mathrm{O}$ change upon full hydration/dehydration of $\mathrm{NCa} / \mathrm{NCh}$ samples was confirmed with an error below $1 \%$.

The FT-Raman spectrum was recorded after defined time periods of exposure, using small amounts of sample. All experiments were performed at $24^{\circ} \mathrm{C}$ ambient temperature and repeated at least three times. The measurements for the dehydration study at higher temperatures were taken under ambient RH conditions.

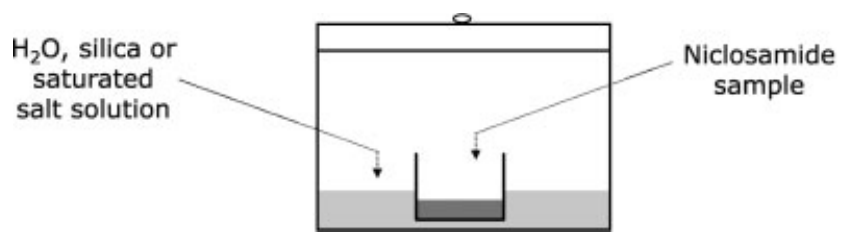

Figure 2. Schematic representation of the experimental apparatus. 


\section{FT-Raman spectra}

The FT-Raman spectra were recorded on a RFS-100 Bruker FT-Spectrometer, equipped with a $\mathrm{Nd}$ :YAG laser with excitation wavelength of $1064 \mathrm{~nm}$, with laser power set to $400 \mathrm{~mW}$.

A few milligrams of the sample were placed in a small aluminum sample cup and slightly packed. Each spectrum corresponds to the average of two repeated measurements of 100 scans each and $2 \mathrm{~cm}^{-1}$ resolution.

In some experiments, it has been reported that the sample temperature can rise significantly due to laser exposure, ${ }^{30,31}$ which can subsequently lead to polymorphic transformations or loss of solvent molecules. The effect of this phenomenon on the present study was evaluated. A sample of NCh was exposed continuously to $400 \mathrm{~mW}$ laser power for $3 \mathrm{~h}$, during which several records of $5 \mathrm{~min}$ each were collected. The comparison of the spectra showed that during the time needed for the record of each spectrum ( $\mathrm{ca}$ 12 min one measurement of 100 scans) no spectral change was noticeable. Since all the FT-Raman spectra reported in this work (using the conditions previously described) were collected in 20 min or less, none of the observed changes can be ascribed to laser exposure.

\section{Theoretical calculations}

Geometry optimization and wavenumber calculations were performed using the Gaussian 03W program package $(\mathrm{G} 03 \mathrm{~W})^{32}$ at the B3LYP level of theory. ${ }^{33,34}$

All molecular structures (monomer and molecular pairs) were fully optimized using the standard all-electron 6$31 G^{*}$ basis set, ${ }^{35}$ using the gradient method. Harmonic vibrational wavenumbers were calculated, using analytical second derivatives, for all optimized geometries in order to confirm the convergence to a minimum. The wavenumbers above $500 \mathrm{~cm}^{-1}$ were scaled by a factor of $0.9614 .^{36}$

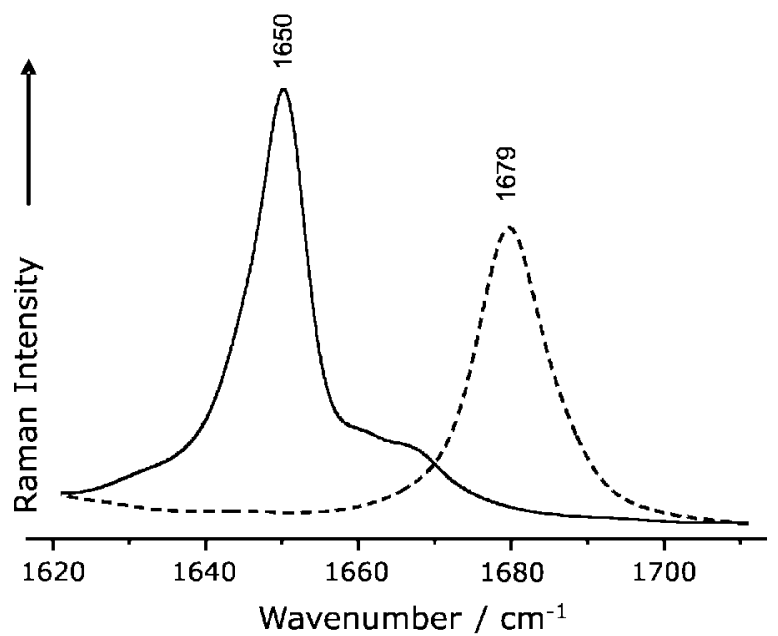

\section{Selection of the most useful spectral regions}

In order to use Raman spectroscopy in the evaluation of kinetic parameters, it is first necessary to identify the distinct bands due to the different polymorphic or pseudopolymorphic forms intervening in the reaction pathway, and then choose the most suitable bands for sample characterization.

All the spectral regions presenting differences between $\mathrm{NCa}$ and NCh forms were evaluated for their suitability to be used in the quantification of the two pseudopolymorphic forms, by considering physical mixtures of known NCa/NCh ratio. In this evaluation, two main criteria were observed. Firstly, the existence of an isosbestic point is required (generally accepted as an indication that only two species exist in the pathway of a reaction, and that they interconvert directly). ${ }^{37}$ Secondly, the number of bands that are required for spectral deconvolution (as the spectral regions that can be described using two single bands in deconvolution process are less prone to 'over-parameterization' errors). The Raman spectra of NCa and NCh in the 620-646 and 1620-1710 $\mathrm{cm}^{-1}$ spectral regions, which were found to be the most adequate for the present study, are shown in Fig. 3. The bands observed in these regions are most likely related to the stretching mode of the oscillator $\mathrm{C}=\mathrm{O}\left(1650-1679 \mathrm{~cm}^{-1}\right)$ and the outof-plane deformation of the oscillator $\mathrm{N}-\mathrm{H}\left(631-635 \mathrm{~cm}^{-1}\right)$, as discussed below.

\section{Determination of kinetic parameters}

Different kinetic models $[f(\alpha)=k t$, where $\alpha$ stands for the fractional of conversion] have been defined for characterizing the solid-state reaction mechanisms, such as the present pseudopolymorphic conversions (Table 1). ${ }^{38-41}$ By plotting $f(\alpha)$ vs time-of-reaction, a linear relation is obtained, with the corresponding slope giving the reaction rate of the process.

The observed intensity of the band associated to component $\mathrm{A}\left(I_{\mathrm{A}}\right)$ can be described as $I_{\mathrm{A}}=\delta_{\mathrm{A}} \times C_{\mathrm{A}}$ where $\delta_{\mathrm{A}}$ is the Raman activity (intrinsic intensity) of the corresponding

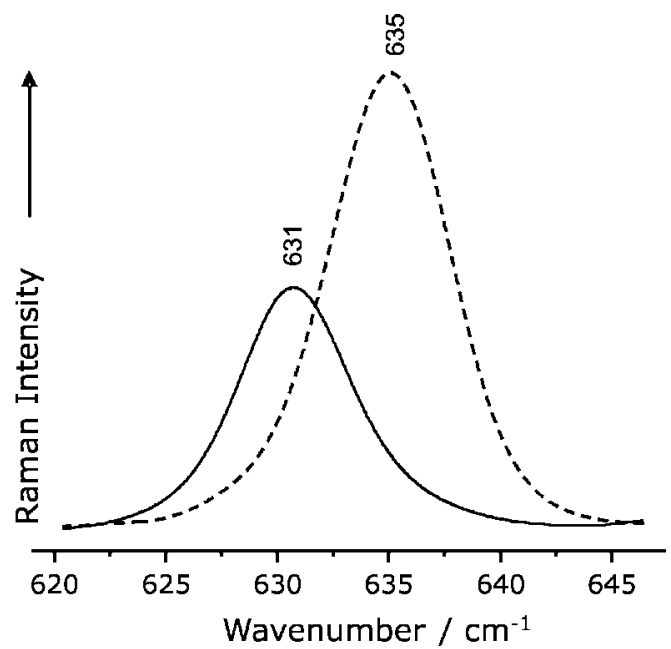

Figure 3. Comparison of the FT-Raman spectra of NCa (solid line) and NCh (dashed line) in the 1620-1710 and 620-646 cm-1 spectral regions. 
Table 1. Solid-state reaction rate equations and mechanisms ${ }^{38-41}$

\begin{tabular}{lccc}
\hline Model & Equation, $f(\alpha)=k t^{\mathrm{a}}$ & Rate-controlling mechanism & Mechanism classification $^{\mathrm{b}}$ \\
\hline M1 & $\alpha^{1 / 4}$ & Power law & Nucleation \\
M2 & $\alpha^{1 / 3}$ & Power law & Nucleation \\
M3 & $\alpha^{1 / 2}$ & Power law & Nucleation \\
M4 & $\alpha^{3 / 2}$ & Power law & Nucleation \\
M5 & $1-\alpha$ & One-dimensional phase boundary reaction (zero-order) & \\
M6 & $1-(1-\alpha)^{1 / 2}$ & Two-dimensional phase boundary reaction (cylindrical symmetry) & Geometrical contraction \\
M7 & $1-(1-\alpha)^{1 / 3}$ & Three-dimensional phase boundary reaction (spherical symmetry) & Geometrical contraction \\
M8 & $-\ln (1-\alpha)$ & Mampel equation & Reaction order \\
M9 & {$[-\ln (1-\alpha)]^{1 / 2}$} & Avrami-Erofeev equation $n=1 / 2$ & Nucleation \\
M10 & {$[-\ln (1-\alpha)]^{1 / 3}$} & Avrami-Erofeev equation $n=1 / 3$ & Nucleation \\
M11 & {$[-\ln (1-\alpha)]^{1 / 4}$} & Avrami-Erofeev equation $n=1 / 4$ & Nucleation \\
M12 & {$[-\ln (1-\alpha)]^{2 / 3}$} & Avrami-Erofeev equation $n=2 / 3$ & Nucleation \\
M13 & $\alpha$ & One-dimensional diffusion & Reaction Order \\
M14 & $\alpha^{2}$ & Two-dimensional diffusion & Diffusion \\
M15 & $(1-\alpha) \ln (1-\alpha)+\alpha$ & Zero-order mechanism (Polany-Wigner equation) & Diffusion \\
M16 & {$\left[1-(1-\alpha)^{1 / 3}\right]^{2}$} & Three-dimensional diffusion (Jander equation) & Diffusion \\
M17 & $1-(2 \alpha / 3)-(1-\alpha)^{2 / 3}$ & Thronsional diffusion (Ginstling-Brounshtein equation) & Diffusion
\end{tabular}

${ }^{\mathrm{a}} \alpha$ stands for $\mathrm{NCa} \rightarrow \mathrm{NCh}$ or $\mathrm{NCh} \rightarrow \mathrm{NCa}$ degree of conversion; $k$ is the rate constant of the conversion reaction; $t$ is the time-of-exposure to water atmosphere.

${ }^{b}$ Solid-state kinetic reactions can be mechanistically classified as nucleation, geometrical contraction, diffusion, and reaction order models, according to Table 1 of Ref. 39.

vibrational mode, and $C_{A}$ is the relative concentration of component $\mathrm{A}$ in the sample (within the scope of the present work, relative concentration of a given polymorphic or pseudopolymorphic form). Thus, the values of the fractional of conversion can be determined by using the relative intensity ratio of the Raman bands ascribed to each form, $\mathrm{NCa}$ and NCh. That is, the values of the fractional of hydration $\left(\alpha_{\mathbf{h}}\right)$ and of dehydration $\left(\alpha_{\mathrm{d}}\right)$ at a particular time-of-reaction (of time-of-exposure to $\mathrm{RH}$ conditions or of time-of-storage at a given temperature) can be determined as

$$
\alpha_{\mathrm{h}}(t)=I_{\mathrm{NCh}} /\left[I_{\mathrm{NCh}}+\left(\delta_{\mathrm{NCh}} / \delta_{\mathrm{NCa}}\right) I_{\mathrm{NCa}}\right]
$$

and

$$
\alpha_{\mathrm{d}}(t)=I_{\mathrm{NCa}} /\left[I_{\mathrm{NCa}}+\left(\delta_{\mathrm{NCa}} / \delta_{\mathrm{NCh}}\right) I_{\mathrm{NCh}}\right]
$$

respectively ( $I$ stands for intensity of the bands ascribed to the $\mathrm{NCh}$ and NCa forms at instant $t$ of reaction, and $\delta$ stands for the intrinsic intensitiy of the vibrational mode considered). By definition, $\alpha_{\mathrm{h}}+\alpha_{\mathrm{d}}=1$.

The different kinetic models of Table 1 were considered in order to identify the mechanism underlying both the $\mathrm{NCa}$ $\rightarrow \mathrm{NCh}$ and the NCh $\rightarrow$ NCa conversions.

\section{Spectral band deconvolution and mathematical treatment}

Band areas were determined by fitting to the spectral regions in study, Lorentzian or Gaussian functions, after performing a linear baseline correction employing three points (Supplementary Information). The $\delta_{\mathrm{NCh}} / \delta_{\mathrm{NCa}}$ ratio, required to obtain the values of the fractional of transformation, $\alpha_{\mathrm{NCa}}$ and $\alpha_{\mathrm{NCh}}$, from the measured band intensities (Eqns (1) and (2)), were determined by fitting procedures, using physical mixtures of both components with defined well-known composition (NCh molar fractions of $0.00,0.10$, $0.25,0.50,0.75,0.90$, and 1.00 were used). Regarding the hydration/dehydration processes of niclosamide, the relation between the intrinsic intensities of the hydrated and anhydrous forms $\left(\delta_{\mathrm{NCh}} / \delta_{\mathrm{NCa}}\right)$ was found to be $0.59(2)$ and $1.14(1)$ for the $1620-1710$ and $620-646 \mathrm{~cm}^{-1}$ regions, respectively.

Different standard statistical criteria may be used to determine the aggregate deviation of a set of measured points from the calculated linear relationship. The correlation coefficient $\left(R^{2}\right)$ and the standard error of the slope of the regression line $\left(s_{\mathrm{b}}\right)$ are the most commonly used. Some authors ${ }^{38,42}$ have reported the inadequacies of using $r$-value as the sole determinant of the applicability of a particular kinetic model, particularly for distinguishing between mechanisms that yield similar linear correlation coefficients $\left(R^{2}\right)$. Davis and Pryor ${ }^{42}$ pointed out the advantages of using $s_{\mathrm{b}}$-values instead. In this work, the quality of the linear fit obtained for each kinetic model tested (Table 1) is determined by considering both $R^{2}$ - and $s_{\mathrm{b}}$-values.

\section{RESULTS AND DISCUSSION}

Figure 4 compares the Raman spectra of NCa and NCh pure forms (bottom and top, respectively) in the $100-1700 \mathrm{~cm}^{-1}$ 


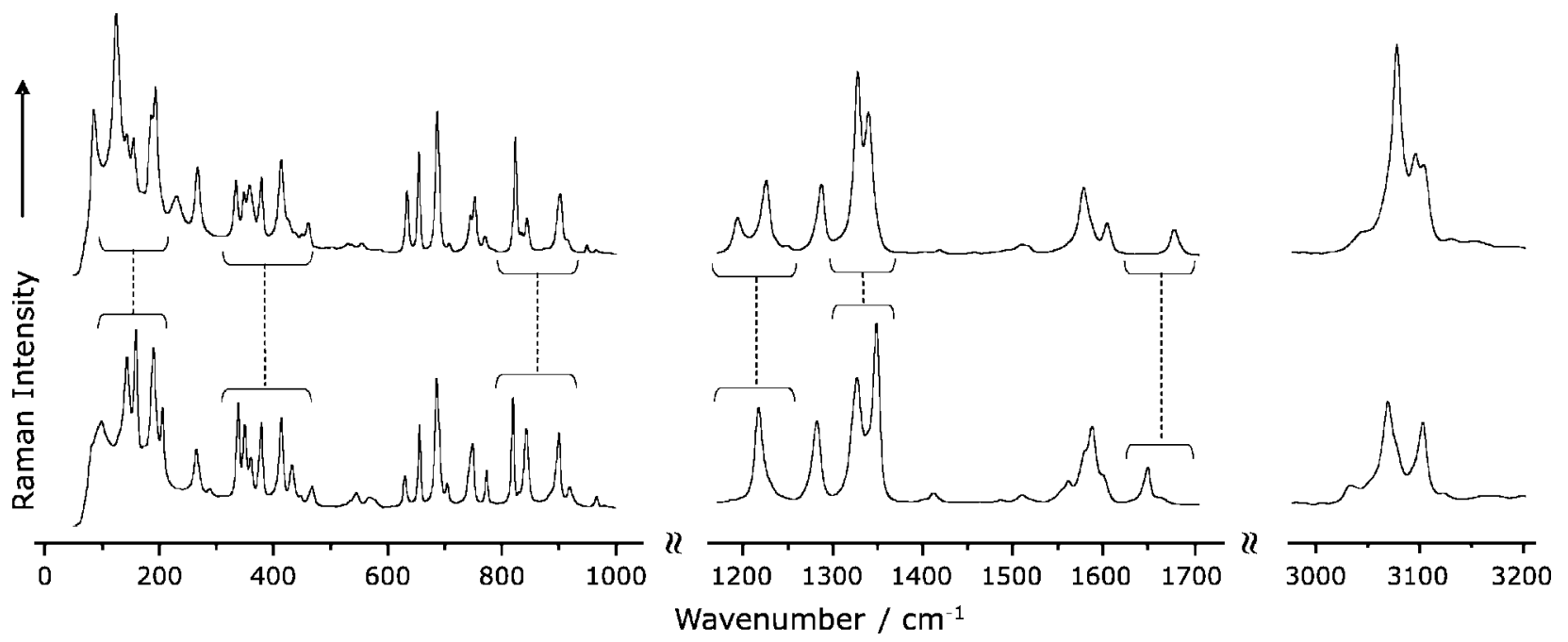

Figure 4. FT-Raman spectra of NCa (bottom) and NCh (top) in the 50-1100, 1200-1700 and 3000-3200 $\mathrm{cm}^{-1} \mathrm{spectral}^{\mathrm{regions}}$. The marked regions show the most pronounced differences between the two forms.

and $3000-3200 \mathrm{~cm}^{-1}$ spectral regions. The two spectra present differences that are spread out through almost the entire spectral range.

The regions with most pronounced differences are marked in Fig. 4 and the tentative assignments of the most relevant bands in these regions are presented in Table 2. Some of the differences between $\mathrm{NCa}$ and $\mathrm{NCh}$ spectra can be associated with the structural changes promoted by hydration. For instance, the $v \mathrm{C}=\mathrm{O}$ stretching mode moves from $1650 \mathrm{~cm}^{-1}$ in $\mathrm{NCa}$ to $1679 \mathrm{~cm}^{-1}$ in $\mathrm{NCh}$, indicating that the carbonyl oxygen atom is more strongly engaged in hydrogen bonding in the anhydrous form. On the other hand, the symmetric and the antisymmetric $v \mathrm{NO}_{2}$ stretching modes move downwards upon hydration from 1348 to $1328 \mathrm{~cm}^{-1}$ and from 1517 to $1504 \mathrm{~cm}^{-1}$, respectively. These observations suggest that the water molecule is probably located close to the $\mathrm{NO}_{2}$ group and not bound to the carbonyl group.

The modes combining stretching and bending of both $\mathrm{C}-\mathrm{O}-\mathrm{H}$ and $\mathrm{C}-\mathrm{N}-\mathrm{H}$ groups $(\mathrm{C}-\mathrm{X}$ stretch and $\mathrm{C}-\mathrm{X}-\mathrm{H}$ bend) are also affected by hydration, but the structural meaning of these changes is not straightforward.

$A b$ initio calculations using a molecular pair approach ${ }^{22}$ can be used to predict the shifts associated with pairwise intermolecular contacts, and assist a full vibrational assignment of different crystal forms. Although such assignment is out of the scope of the present work, calculations with a few pairs suggest that the observed shifts may result from the increase of hydrogen bond contacts of the $\mathrm{OH}$ group (for instance, due to niclosamide $\cdots \mathrm{H}_{2} \mathrm{O}$ association) and the decrease of hydrogen bond contacts of the $\mathrm{C}=\mathrm{O}$ group.

\section{Hydration process of NCa}

Figure 5 shows the sequential change of the spectral region assigned to the $\mathrm{C}=\mathrm{O}$ stretching mode $\left(1620-1710 \mathrm{~cm}^{-1}\right)$ as
Table 2. Most relevant Raman bands presenting different wavenumbers in the $\mathrm{NCa}$ and $\mathrm{NCh}$ forms and their proposed assignments

\begin{tabular}{lrc}
\hline NCa & NCh & Tentative assignment $^{\text {a }}$ \\
\hline 339 & 333 & Ring out-of-plane deformation \\
631 & 635 & N-H out-of-plane deformation \\
820 & 824 & CCN bend \\
1218 & 1226 & C-O stretch + C-O-H bend \\
1283 & 1289 & HN-C open-stretch \\
1327 & 1340 & C-O-H bend + C-O stretch \\
1348 & 1328 & $\mathrm{NO}_{2}$ sym stretch \\
1517 & 1504 & $\mathrm{NO}_{2}$ asym stretch \\
1568 & 1559 & $\mathrm{HN}^{\mathrm{b}} \mathrm{C}$ bend stretch \\
1650 & 1680 & $\mathrm{C}=\mathrm{O}^{\mathrm{b}}$ stretch \\
\hline
\end{tabular}

${ }^{\text {a }}$ Based on IR and Raman wavenumbers (in $\mathrm{cm}^{-1}$ ) and ab initio calculations at the B3LYP/6-31G* level for the isolated molecule. ${ }^{b}$ In-phase and out-of-phase combinations of HNC bend with NC stretch. ${ }^{43}$

a function of the time-of-exposure to water-saturated atmosphere, at $24^{\circ} \mathrm{C}$. The time-dependent intensities observed in the $620-646 \mathrm{~cm}^{-1}$ spectral region present a similar behavior.

The first evidences of the pseudopolymorphic transformation are detectable after $96 \mathrm{~h}$ of exposure. On the other hand, after $240 \mathrm{~h}$ of exposure the band ascribed to the $\mathrm{NCa}$ form is just a weak band, which disappears after more than $264 \mathrm{~h}$. Larger times of exposure did not give rise to any further eye-observable spectral change.

The values of the fractional of hydration $\alpha_{\mathrm{h}}$ were fitted to the different kinetic models listed in Table 1, and it was found that the hydration of NCa is better described by the Avrami-Erofeev random nucleation approach. Table 3 shows the kinetic results obtained for the NCa hydration 

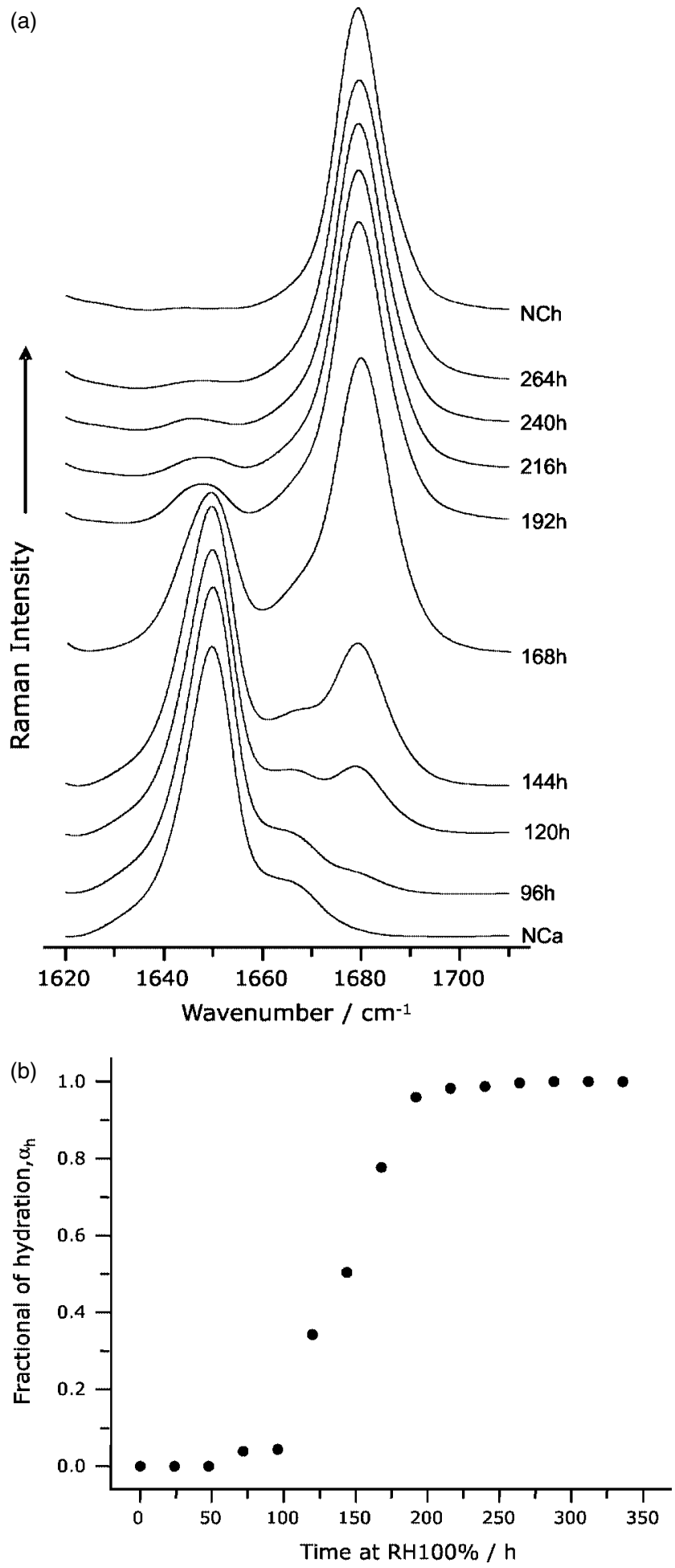

Figure 5. (a) Partial Raman spectra $\left(1620-1710 \mathrm{~cm}^{-1}\right.$ region) of $\mathrm{NCa}$ samples stored at $100 \% R H\left(24^{\circ} \mathrm{C}\right)$ for up to 2 weeks; (b) plot of the measured $\alpha_{\mathrm{h}}$ ratio as a function of time-of-exposure to the $100 \% \mathrm{RH}$ environment. Equivalent figures were also obtained for the $620-646 \mathrm{~cm}^{-1}$ spectral region. process, using the Raman measurements. Although the obtained $R^{2}$ - and $s_{\mathrm{b}}$-values for M10 and M11 kinetic models are somewhat similar, the M10 was assumed to yield a better description of the overall results (two spectroscopic regions). Within this assumption, the hydration of NCa is a one-step random nucleation process, described by the Avrami-Erofeev equation of exponent $1 / 3$, with a rate constant of $c a 0.007 \mathrm{~h}^{-1}$.

It should be mentioned that all the spectra recorded during the NCa-to-NCh conversion can be described by the weighted sum of the pure NCa and NCh spectra, without additional features or missing bands. The absence of features assignable to metastable or intermediate species is consistent with the single-step mechanism.

\section{Dehydration process of NCh}

As found for the hydration process, the Raman spectra of samples during the dehydration process do not reveal the presence of intermediate forms, i.e. additional or missing spectral features relative to those belonging to $\mathrm{NCa}$ and NCh. The presence of intermediate (metastable) form during the dehydration process has been observed by Raman spectroscopy in the case of theophylline, for which a two-step dehydration mechanism was proposed: only after the loss of a significant amount of water (up to ca $17 \%$ ), the 'hydrate-type' structure reorganizes into the 'anhydrous-type' structure. ${ }^{15}$ For niclosamide, the structure reorganization from $\mathrm{NCh}$ to $\mathrm{NCa}$ seems to be concomitant with water loss.

As shown in Fig. 6, the first evidences of dehydration appear after more than $24 \mathrm{~h}$ of exposure to $\mathrm{RH}=0 \%$, at $24^{\circ} \mathrm{C}$. On the other hand, after $120 \mathrm{~h}$ of exposure, the band ascribed to the NCh form is just a weak shoulder, which completely disappears after $144 \mathrm{~h}$ of exposure (6 days). Larger times of exposure did not give rise to any further eye-observable spectral change.

After fitting the $\alpha_{\mathrm{h}}$ quantity to the different kinetic models listed in Table 1, as mentioned before in the hydration section, it was found that for both spectral regions (620-646 and $1620-1710 \mathrm{~cm}^{-1}$ ) the dehydration of $\mathrm{NCh}$ is better described by the Avrami-Erofeev random nucleation approach. Table 4 shows the best kinetic results obtained for the NCh dehydration process, using the Raman measurements. According to these experimental results, we can assume that the dehydration of NCh is a one-step random nucleation process, described by the Avrami-Erofeev equation of exponent $1 / 2$, with a constant rate of $c a 0.0157 \mathrm{~h}^{-1}$, which corresponds to a half-life time of $c a 63 \mathrm{~h}$.

The onset of temperature-dependent dehydration of NCh lies above $35^{\circ} \mathrm{C}$. At $35^{\circ} \mathrm{C}$, no evidences of dehydration of $\mathrm{NCh}$ are found after 1 week of exposure - and this is an important information for the storage of niclosamide worldwide. On the other hand, at $45^{\circ} \mathrm{C}$ the dehydration of $\mathrm{NCh}$ begins after less than $24 \mathrm{~h}$ of exposure but it is not complete after more than 10 days of exposure (Fig. 7). At 
Table 3. Values of rate constant of hydration $(k)$, standard deviation of the slope $\left(s_{\mathrm{b}}\right)$, correlation coefficient $\left(R^{2}\right)$, and times of half-hydration $\left(t_{1 / 2}\right)$ and complete hydration $\left(t_{h}\right)$, obtained for the best linear fits $f(\alpha)$ for the two spectral regions considered

\begin{tabular}{|c|c|c|c|c|c|c|c|}
\hline $\begin{array}{l}\text { Spectral } \\
\text { region } \mathrm{cm}^{-1}\end{array}$ & Model & $f(\alpha)$ & $k \mathrm{~h}^{-1}$ & $s_{\mathrm{b}}$ & $R^{2}$ & $t_{1 / 2}{ }^{\mathrm{a}} \mathrm{h}^{-1}$ & $t_{\mathrm{h}}^{\mathrm{b}} \mathrm{h}^{-1}$ \\
\hline \multirow[t]{2}{*}{$1620-1710$} & M10 & $0.00754 t-0.14412$ & 0.00754 & 0.00059 & 0.9649 & 136 & 319 \\
\hline & M11 & $0.00625 t+0.00240$ & 0.00625 & 0.00042 & 0.9733 & 145 & 295 \\
\hline $620-646$ & M10 & $0.00664 t-0.09544$ & 0.00664 & 0.00051 & 0.9597 & 147 & 319 \\
\hline
\end{tabular}

a Time for half-hydration [ $f(\alpha)$ is equal to 0.88 and 0.91 for M10 and M11, respectively, using $\alpha=0.5]$.

b Time for total hydration [ $f(\alpha)$ is equal to 2.26 and 1.84 for M10 and M11, respectively, using $\alpha=0.99999$ ].

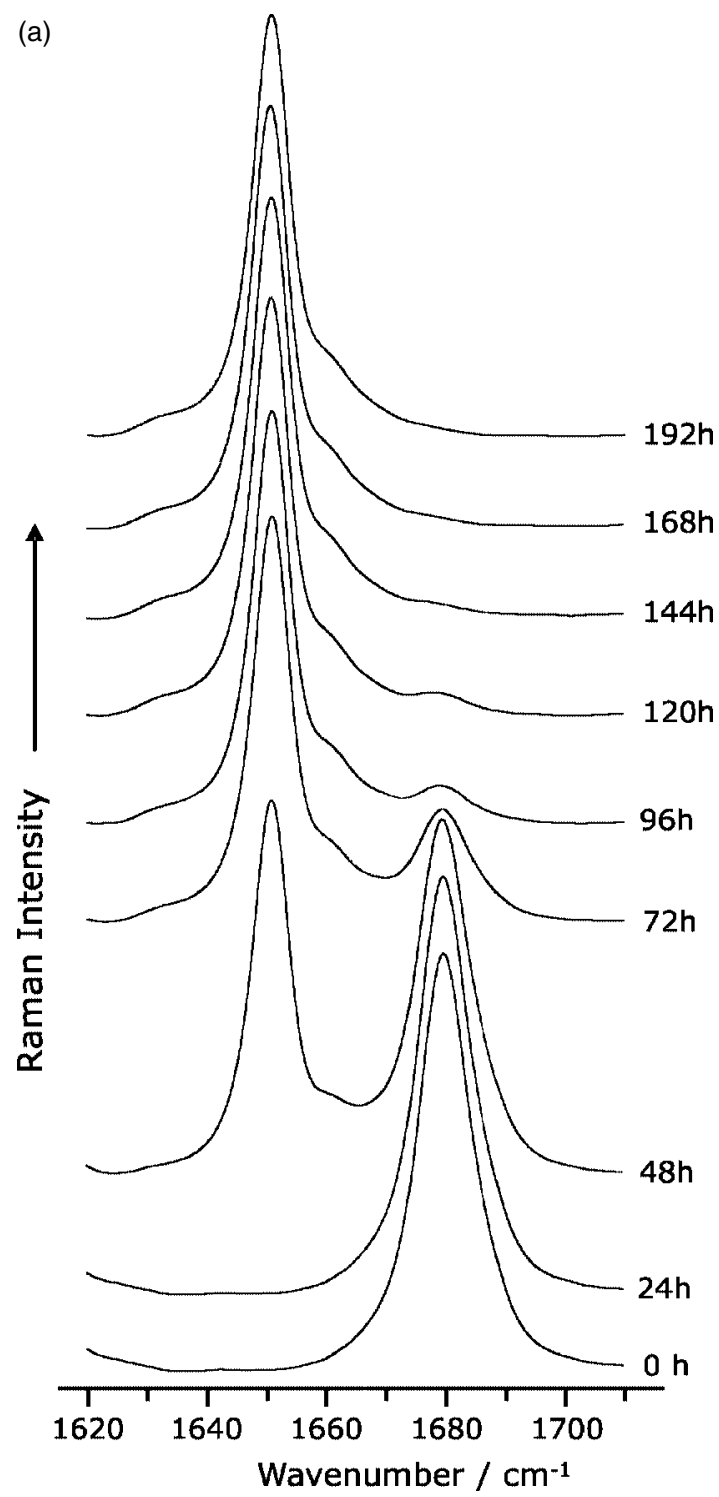

(b)

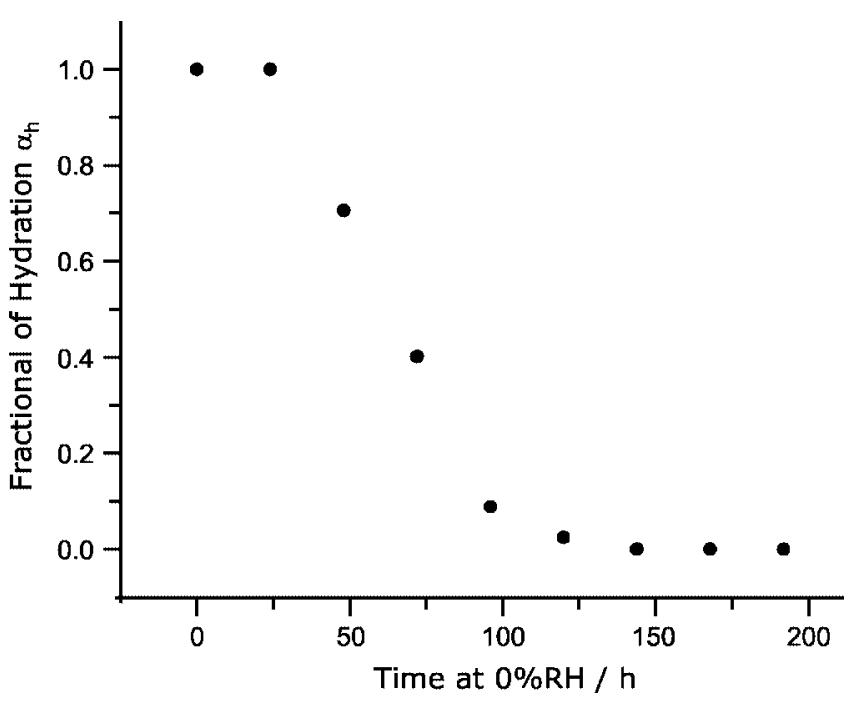

Figure 6. (a) Partial Raman spectra $\left(1620-1710 \mathrm{~cm}^{-1}\right)$ of NCh samples stored at $0 \% R H\left(24^{\circ} \mathrm{C}\right)$ for up to 1 week; (b) plot of the measured $\alpha_{\mathrm{h}}$ ratio as a function of time-of-exposure to the $0 \% \mathrm{RH}$ environment. Equivalent figures were also obtained for the $620-646 \mathrm{~cm}^{-1}$ spectral region. 
Table 4. Values of rate constant of dehydration $(k)$, standard deviation of the slope $\left(s_{\mathrm{b}}\right)$, correlation coefficient $\left(R^{2}\right)$, and times of half-dehydration $\left(t_{1 / 2}\right)$ and complete dehydration $\left(t_{h}\right)$, obtained for the best linear fits $f(\alpha)$ obtained for the two spectral regions considered

\begin{tabular}{lccccrr}
\hline $\begin{array}{l}\text { Spectral } \\
\text { region } \mathrm{cm}^{-1}\end{array}$ & Model & $f(\alpha)$ & $k \mathrm{~h}^{-1}$ & $s_{\mathrm{b}}$ & $R^{2}$ & $t_{1 / 2}{ }^{\mathrm{a}} \mathrm{h}^{-1}$ \\
\hline $1620-1710$ & M9 & $0.0175 t-0.2097$ & 0.0175 & 0.00227 & 0.9662 & 59 \\
$620-646$ & M9 & $0.0139 t-0.0996$ & 0.0139 & 0.00213 & 0.9537 & 67 \\
\hline
\end{tabular}

a Time for half-dehydration [ $f(\alpha)$ is equal to 0.83 for M9, using $\alpha=0.5]$.

b Time for total dehydration [ $f(\alpha)$ is equal to 3.39 for M9, using $\alpha=0.99999]$.

(a)

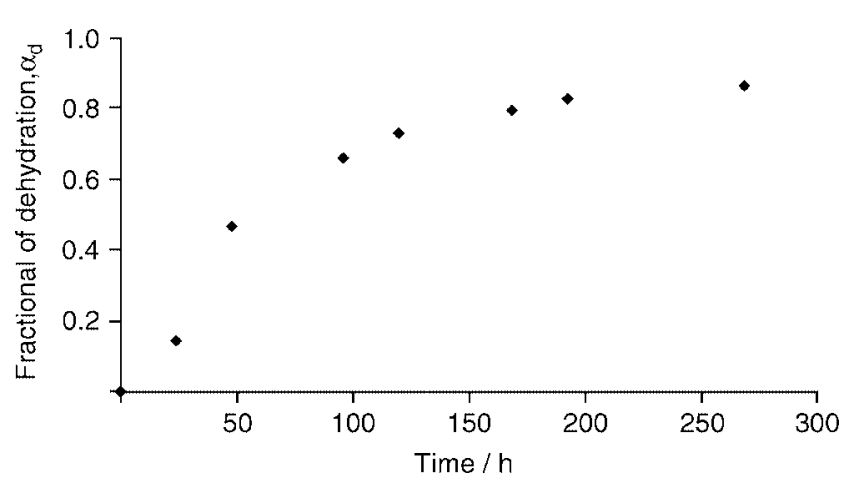

(b)

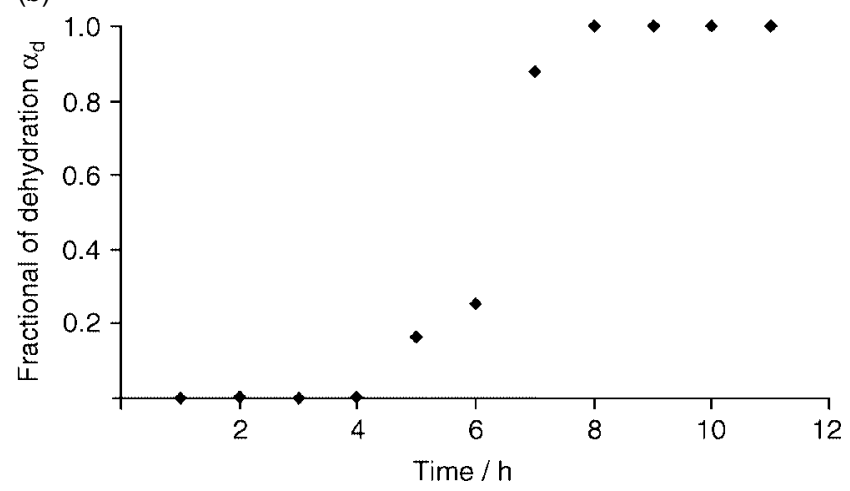

Figure 7. Plot of fractional of hydration $\left(\alpha_{\mathrm{h}}\right)$ as a function of time-of-exposure to temperatures of $45^{\circ} \mathrm{C}$ (up) and $60^{\circ} \mathrm{C}$ (bottom). Data derived from the $1620-1710 \mathrm{~cm}^{-1}$ spectral region.

$60{ }^{\circ} \mathrm{C}$, the dehydration of $\mathrm{NCh}$ is complete after about $8 \mathrm{~h}$ of exposure. As expected, the time required to complete dehydration increases as temperature decreases, being of the order of $\mathrm{ca} 8 \mathrm{~h}$ and more than $264 \mathrm{~h}$ at 60 and $45^{\circ} \mathrm{C}$, respectively.

\section{Critical RH for hydration/dehydration process}

To the best of our knowledge, the critical RH conditions for the NCa $\leftrightarrow \mathrm{NCh}$ conversion have not been evaluated.

During processing steps like crystallization, lyophilization, wet granulation, and aqueous film-coating or spraydrying, pharmaceutical solids may come in contact with water. Furthermore, drug substances and drug products are submitted to different temperatures and relative humidities during storage (namely, due to climatic conditions), giving rise to unexpected hydration or dehydration aging phenomena that are known to affect several drug properties, such as solubility, dissolution rate, stability, and bioavailability. ${ }^{12,44}$

As described above, the exposure to extreme $R H$ values (0 and 100\%) results in total $\mathrm{NCa} \leftrightarrow \mathrm{NCh}$ interconversion in substantially less than 2 weeks. However, at intermediate $R H$ values, the same processes were found to occur in a much larger time scale. In fact, for storage periods of up to 1 month it was not possible to identify the thermodynamic critical RH value.

The results obtained after a 2 -week period are illustrated in Fig. 8. The Raman spectra of $\mathrm{NCa}$ samples stored at different $R H$ values show evidences of the presence of $\mathrm{NCh}$ form only for $\mathrm{RH}>90 \%$, and the band assigned to the $\mathrm{NCa}$ form remains up to $R H=97 \%$. For the reverse process (NCh $\rightarrow \mathrm{NCa}$ ), the first evidences of NCh dehydration can only be observed in the Raman spectrum of the sample stored at $R H \leq 6 \%$.

\section{CONCLUSIONS}

FT-Raman spectroscopy was used to quantify the anhydrate and hydrate forms of niclosamide crystals, mostly because of its high sensitivity to the strong intermolecular interactions present in these systems. The observed spectral changes suggest that upon hydration the carbonyl group becomes unbound or weakly bound and the water molecule is probably located close to the $\mathrm{NO}_{2}$ and $\mathrm{OH}$ groups of two neighboring molecules. Among the several spectral features sensitive to the degree of hydration/dehydration, the bands assigned to the $\mathrm{C}=\mathrm{O}$ stretching mode $\left(1650-1679 \mathrm{~cm}^{-1}\right)$ and the $\mathrm{N}-\mathrm{H}$ out-of-plane deformation mode $\left(631-635 \mathrm{~cm}^{-1}\right)$ present optimal conditions for sample characterization.

Both hydration and dehydration process were found to follow one-step random nucleation mechanisms. The absence of spectral features not ascribed to pure NCa and NCh during the hydration/dehydration processes indicates the absence of intermediate forms and is consistent with the single-step mechanisms. At $R H=100 \%$ and $24^{\circ} \mathrm{C}$, the hydration of 
(a)

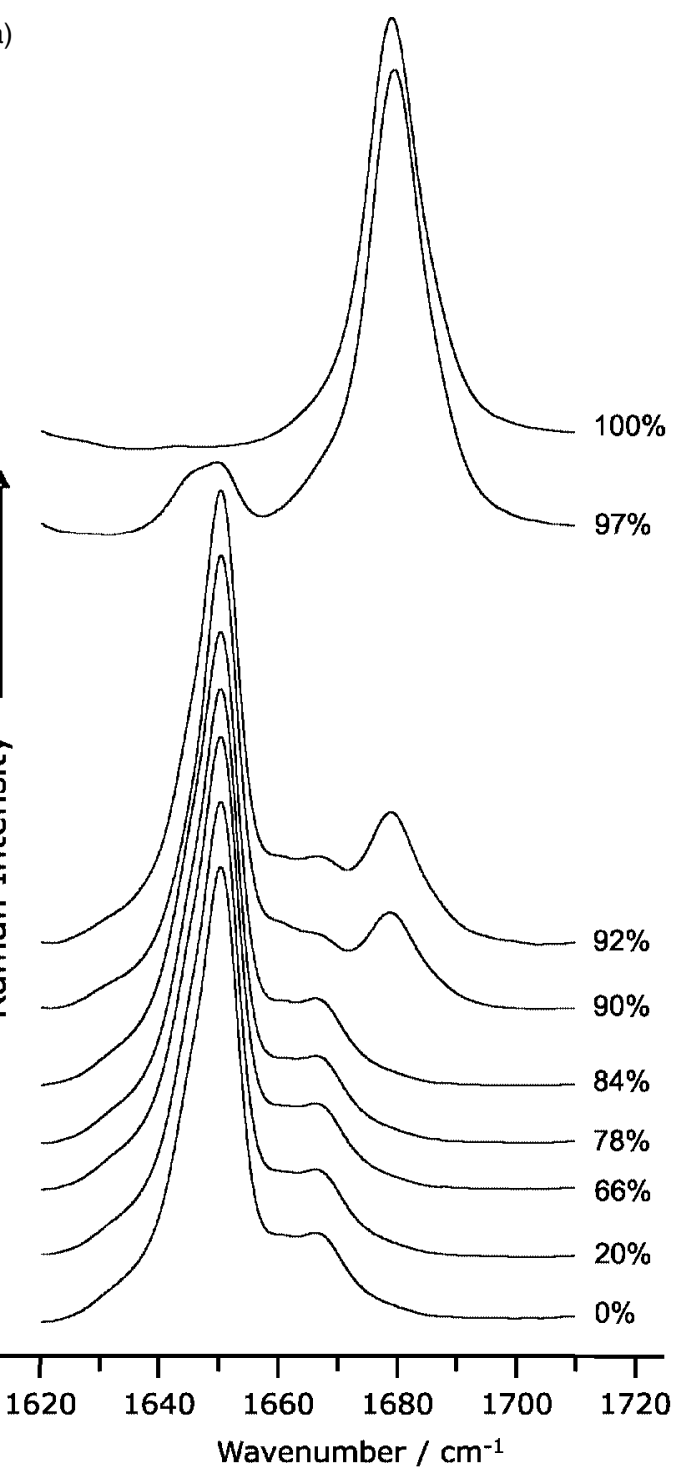

(b)

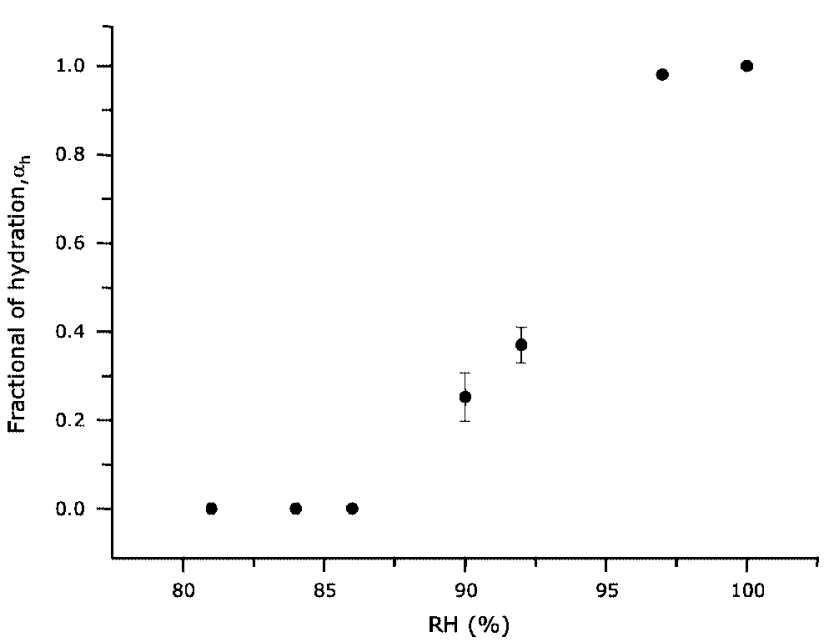

Figure 8. Partial Raman spectra (1620-1710 $\mathrm{cm}^{-1}$ region) of NCa samples stored at different $R H$ values for 2 weeks, at $24^{\circ} \mathrm{C}$ (left side) and plot of the measured $\alpha_{\mathrm{h}}$ ratio as a function of the $R H$ values (error bars included). The $\alpha_{\mathrm{h}}$ ratio is $0.25,0.37$, and 0.98 for the samples exposed to $R H=90,92$, and $97 \%$ respectively.

$\mathrm{NCa}$ is described by the Avrami-Erofeev equation for onestep random nucleation process with exponent $1 / 3$. The rate constant of hydration is $c a 0.007 \mathrm{~h}^{-1}$, which corresponds to a half-life time of $c a 142 \mathrm{~h}$. On the other hand, the dehydration of NCh, at $R H=0 \%$ and $24{ }^{\circ} \mathrm{C}$, is best described by the Avrami-Erofeev equation of exponent 1/2, with a rate constant of $c a 0.0157 \mathrm{~h}^{-1}$, which corresponds to a half-life time of $c a 63 \mathrm{~h}$. In addition, the onset of the temperaturedependent dehydration of NCh was found to be above $35^{\circ} \mathrm{C}$ (and below $45^{\circ} \mathrm{C}$ ).

The threshold $R H$ values for the $\mathrm{NCa} \leftrightarrow \mathrm{NCh}$ processes within 2 weeks were determined. The threshold for hydration of $\mathrm{NCa}$ is $\mathrm{ca} 90 \% \mathrm{RH}$, while for dehydration of $\mathrm{NCh}$ is $\mathrm{ca}$ $6 \% R H$, showing that for a 2 -week period, no NCa $\leftrightarrow \mathrm{NCh}$ interconversion occurs over a wide range of $R H$ values.

\section{Supporting Information}

Supporting information may be found in the online version of this article.

\section{Acknowledgements}

The authors acknowledge financial support from the Portuguese Foundation for Science and Technology (FCT) - Laboratório Associado CICECO and Unidade de Química-Física Molecular. MS also acknowledges FCT for a Ph.D. grant, SFRH/BD/23400/2005.

\section{REFERENCES}

1. Burger A. Pharm. Int. 1983; 4: 186.

2. Caira MR. Top. Curr. Chem. 1998; 198: 163.

3. Haleblian J, McCrone W. J. Pharm. Sci. 1969; 58: 911.

4. Dunitz JD, Bernstein J. Acc. Chem. Res. 1995; 28: 193.

5. Phadnis NV, Suryanarayanan R. J. Pharm. Sci. 1997; 86: 1256. 
6. Giordano F, Gazzaniga A, Moyano JR, Ventura P, Zanol M, Peveri T, Carima L. J. Pharm. Sci. 1998; 87: 333.

7. Stahl HP. The Problem of Drug Interactions with Excipients in Towards Better Safety of Drugs and Pharmaceutical Products. Elsevier: New York, 1980.

8. Fini G. J. Raman Spectrosc. 2004; 35: 335.

9. Brittain HG. J. Pharm. Sci. 1997; 86: 405.

10. Bauer J, Spanton S, Henry R, Quick J, Dziki W, Porter W, Morris J. Pharm. Res. 2001; 18: 859.

11. Yu LX, Furness MS, Raw A, Outlaw KPW, Nashed NE, Ramos E, Miller SPF, Adams RC, Fang F, Patel RM, Holcombe FO Jr, Chiu Y-y, Hussain AS. Pharm. Res. 2003; 20: 531.

12. Khankari RK, Grant DJW. Thermochim. Acta 1995; 248: 61.

13. Bugay DE. Adv. Drug Deliv. Rev. 2001; 48: 43.

14. Szelagiewicz M, Marcolli C, Cianferani S, Hard AP, Vit A, Burkhard A, von Raumer M, Hofmeier UC, Zilian A, Francotte E, Schenker R. J. Therm. Anal. Calorim. 1999; 57: 23.

15. Amado AM, Nolasco MM, Ribeiro-Claro PJA. J. Pharm. Sci. 2007; 96: 1366.

16. Rodríguez-Spong B, Price $\mathrm{CP}$, Jayasankar A, Matzger AJ, Rodríguez-Hornedoa N. Adv. Drug Deliv. Rev. 2004; 56: 271.

17. O'Brien LE, Timmins P, Williams AC, York P. J. Pharm. Biomed. Anal. 2004; 36: 335.

18. Hausman DS, Cambron RT, Sakr A. Int. J. Pharm. 2005; 299: 19.

19. Pratiwi D, Fawcett JP, Gordon KC, Rades T. Eur. J. Pharm. Biopharm. 2002; 54: 337.

20. Gamberini MC, Baraldi C, Tinti A, Rustichelli C, Ferioli V, Gamberini G. J. Mol. Struct. 2006; 785: 216.

21. Starbuck C, Spartalis A, Wai L, Wang J, Fernandez P, Lindemann CM, Zhou GX, Ge Z. Cryst. Growth Des. 2002; 2: 515.

22. Nolasco MM, Amado AM, Ribeiro-Claro PJA. ChemPhysChem 2006; 7: 2150.

23. Jørgensen A, Rantanen J, Karjalainen M, Khriachtchev L, Räsänen E, Yliruusi J. Pharm. Res. 2002; 19: 1285.

24. van Tonder EC, Maleka TSP, Liebenberg W, Song M, Wurster DE, de Villiers MM. Int. J. Pharm. 2004; 269: 417.

25. Sun Z, Zhang Y. Tuber. Lung Dis. 1999; 79: 319.

26. de Villiers MM, Mahlatji MD, van Tonder EC, Malan SF, Lötter AP, Liebenberg W. Drug Dev. Ind. Pharm. 2004; 30: 581

27. Manek RV, Kolling WM. AAPS PharmSciTech 2004; 5(1): 1.
28. Caira MR, van Tonder EC, de Villiers MM, Lötter AP. J. Inclusion Phenom. Mol. Recognit. Chem. 1998; 31: 1.

29. Weast RC, Astle MJ, Beyer WH (eds). CRC Handbook of Chemistry and Physics a Ready-reference Book of Chemical and Physical Data. CRC Press: Florida, 1983.

30. Marigheto NA, Kemsley EK, Potter J, Belton PS, Wilson RH. Spectrochim. Acta, Part A 1996; 52: 1571.

31. Johansson J, Pettersson S, Taylor LS. J. Pharm. Biomed. Anal. 2002; 30: 1223.

32. Frisch MJ, Trucks GW, Schlegel HB, Scuseria GE, Robb MA, Cheeseman JR, Montgomery JA Jr, Vreven T, Kudin KN, Burant JC, Millam JM, Iyengar SS, Tomasi S, Barone V, Mennucci B, Cossi M, Scalmani G, Rega N, Petersson GA, Nakatsuji $H$, Hada M, Ehara M, Toyota K, Fukuda R, Hasegawa J, Ishida M, Nakajima T, Honda Y, Kitao O, Nakai H, Klene M, Li X, Knox JE, Hratchian HP, Cross JB, Adamo C, Jaramillo J, Gomperts R, Stratmann RE, Yazyev O, Austin AJ, Cammi R, Pomelli C, Ochterski JW, Ayala PY, Morokuma K, Voth GA, Salvador P, Dannenberg JJ, Zakrzewski VG, Dapprich S, Daniels AD, Strain MC, Farkas O, Malick DK, Rabuck AD, Raghavachari K, Foresman JB, Ortiz JV, Cui Q, Baboul AG, Clifford S, Cioslowski J, Stefanov BB, Liu G, Liashenko A, Piskorz P, Komaromi I, Martin RL, Fox DJ, Keith T, Al-Laham MA, Peng CY, Nanayakkara A, Challacombe M, Gill PMW, Johnson B, Chen W, Wong MW, Gonzalez C, Pople JA. Gaussian 03 RB. Gaussian: Pittsburgh, 2003.

33. Becke A. J. Chem. Phys. 1993; 98: 5648.

34. Lee C, Yang W, Parr RG. Phys. Rev. B 1988; 37: 785.

35. Hariharan PC, Pople JA. Theor. Chim. Acta 1973; 28: 213.

36. Scott AP, Radom L. J. Phys. Chem. B 1996; 100: 16502.

37. Girling RB, Shurvell HFA. Vib. Spectrosc. 1998; 18: 77.

38. Brown ME, Galwey AK. Thermochim. Acta 1979; 29: 129.

39. Khawam A, Flanagan DR. J. Pharm. Sci. 2006; 95: 472.

40. Vyazovkin S. J. Comput. Chem. 1997; 18: 393.

41. Ortega A. Int. J. Chem. Kinet. 2002; 34: 223.

42. Davis WHJ, Pryor WA. J. Chem. Educ. 1976; 53: 285.

43. Colthup NB, Daly LH, Wiberley SE. Introduction to Infrared and Raman Spectroscopy. Academic Press: San Diego, 1990.

44. Giron D, Goldbronn C, Mutz M, Pfeffer S, Piechon P, Schwab P. J. Therm. Anal. Calorim. 2002; 68: 453. 